\title{
Keratoconus posticus circumscriptus, cleft lip and palate, genitourinary abnormalities, short stature, and mental retardation in sibs
}

\author{
I D YOUNG, W G MACRAE, H E HUGHES, AND J S CRAWFORD \\ From the Departments of Genetics and Ophthalmology, The Hospital for Sick Children, \\ Toronto, Ontario, Canada
}

SUMMARY This paper describes two sibs in each of whom keratoconus posticus circumscriptus is associated with multiple abnormalities. These include short stature, mental retardation, cleft lip and palate, and vertebral anomalies. The authors have been unable to trace any former reports of an identical condition and suggest that the findings in these children may represent a previously unrecognised malformation syndrome showing probable autosomal recessive inheritance.

Keratoconus posticus circumscriptus (KPC) is a rare congenital abnormality in which the cornea shows an area of increased curvature centrally localised on its posterior surface in association with opacification of the overlying stroma. ${ }^{1}$ On slit lamp examination the cornea appears as if its posterior surface has been indented by a spherical object of a size smaller than that of the cornea itself. In this report we describe two sibs, one boy and one girl, in each of whom KPC is associated with multiple abnormalities.

\section{Case reports}

The affected sibs, who have been under the care of one of us (JSC) since infancy, were the products of the first and fourth pregnancies of healthy unrelated Caucasian parents. The second and fifth pregnancies resulted in spontaneous first trimester abortions, and the third in a healthy male infant. There is no history of congenital abnormality on either side of the family.

CASE 1

The boy, now aged 20 years, is shown in fig 1 . He was born during the 34th week of pregnancy complicated by recurrent vaginal bleeding in the second and third months. Birthweight was $2.09 \mathrm{~kg}$. Examination at three days revealed bilateral cleft lip and palate plus bilateral central posterior corneal opacities. It was noted that the lenses, which were clear, appeared to lie in juxtaposition to the posterior

Received for publication 21 January 1982 surfaces of the corneae. Over the next three weeks the anterior chambers were observed to deepen. Other than recurrent aspiration pneumonia during early infancy, this boy has enjoyed good general

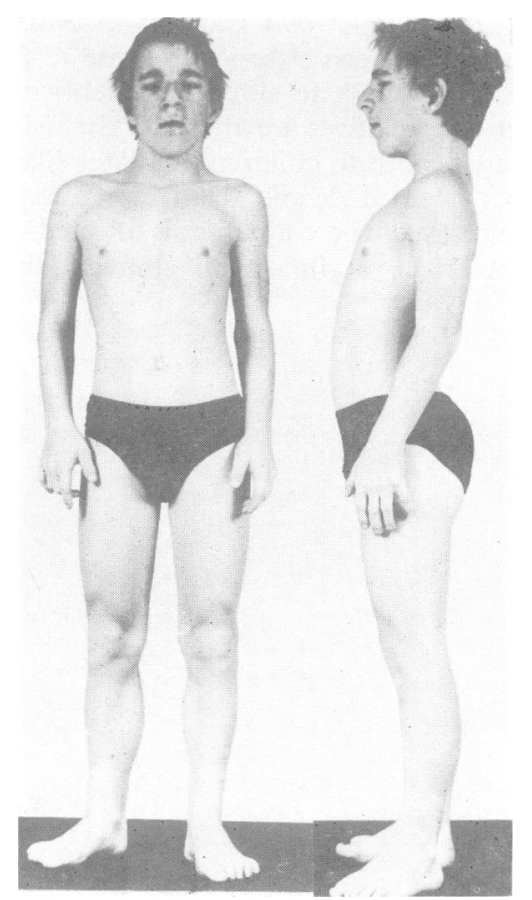

FIG 1 Case 1 aged 18 years. Note the prominent nose and columella, neck webbing, small hands and feet, and abnormal posture owing to the spinal abnormalities. 
health. He has undergone bilateral optical iridectomies, repair of the cleft lip and palate, bilateral orchidopexy and inguinal herniorrhaphies, and bilateral heel cord lengthening. He has had no seizures and has normal hearing.

Developmental progress has been consistently slow. He first walked alone at 3 years and uttered meaningful single words at 4 years. Formal intellectual assessment at the age of 13 years using the Wechsler intelligence scale for children yielded both verbal and performance scale IQ values of 51 . He has always had a happy disposition and has not posed any behaviour problems.

At recent examination growth parameters were: height $146 \mathrm{~cm}(16 \mathrm{~cm}$ below the 3rd centile), span $137 \mathrm{~cm}$, upper to lower segment ratio 1.07 , weight $45.5 \mathrm{~kg}$ ( $5 \mathrm{~kg}$ below the $3 \mathrm{rd}$ centile), and head circumference $54.5 \mathrm{~cm}$. He was noted to have mild maxillary hypoplasia with a prominent nose and columella, neck webbing with a low posterior hair line, a scoliosis convex to the right involving upper thoracic vertebrae, limitation of extension and supination at both elbows, bilateral fifth finger clinodactyly, and short broad feet with bilateral pes cavus. Sexual development has been normal.

Examination with the slit lamp revealed bilateral central corneal leucomata as shown in fig 2. At fundoscopy he was noted to have a coloboma of the right disc (fig 3). Best corrected vision was 20/100 in the right eye and $20 / 80$ in the left eye, with +4 dioptre hyperopia in each eye.

\section{CASE 2}

His sister, now aged 14 years, is shown in fig 4 . She was the product of an uneventful term pregnancy. At birth she weighed $2.4 \mathrm{~kg}$ and was noted to have bilateral central corneal opacities similar to those in her brother, along with left sided ptosis and left sided cleft lip and palate. At two weeks visual examination revealed iridocorneal adhesions. The

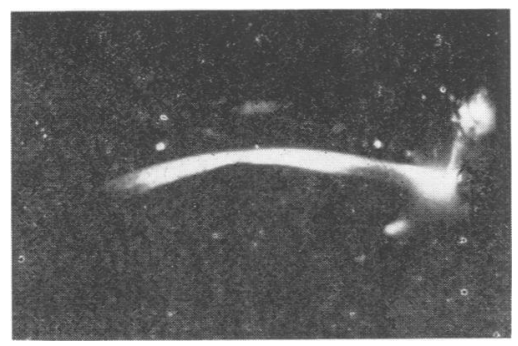

FIG 2 Slit lamp view of the right eye of case 1 aged 14 years. Note the stromal opacification overlying the area of increased curvature on the posterior surface of the cornea.

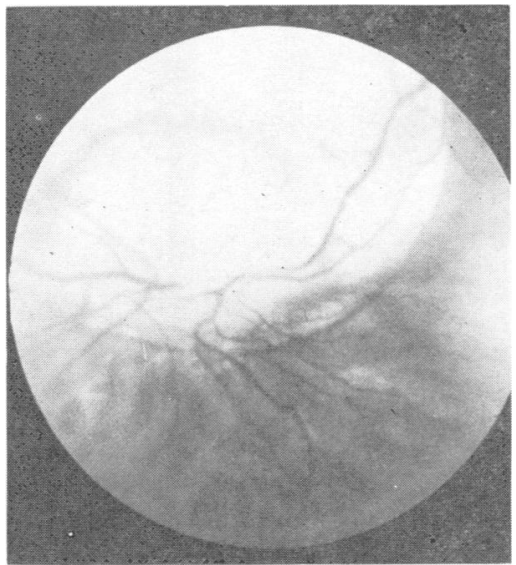

FIG 3 View of the right fundus of case 1 showing the coloboma of the optic disc.

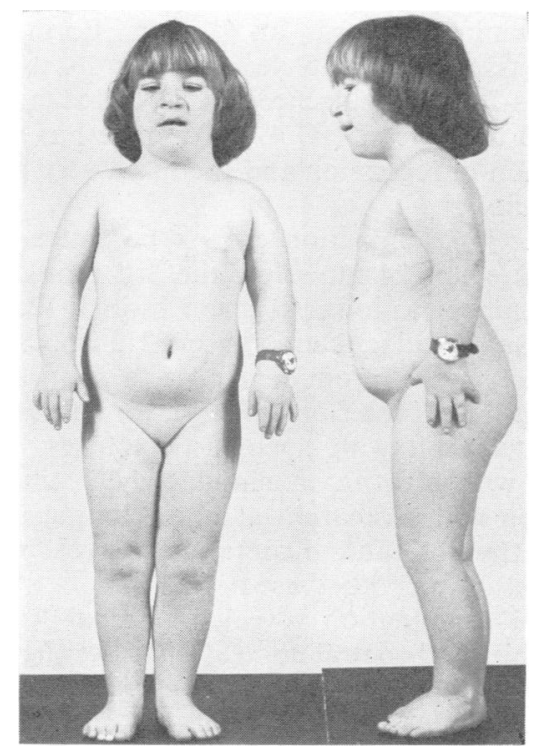

FIG 4 Case 2 aged $11 \frac{1}{2}$ years. Note the neck webbing, short upper limbs, and small hands and feet.

anterior chambers were described as being shallower than normal. The lenses were clear.

During childhood she has had frequent urinary tract infections associated with radiologically proven bilateral ureteric reflux. She has undergone bilateral optical iridectomies, bilateral heel cord lengthening, and repair of the ptosis and cleft lip and palate. Grommets have been inserted on several occasions because of mild conductive deafness associated with serous otitis media. She has had no seizures and is post-menarchal. 


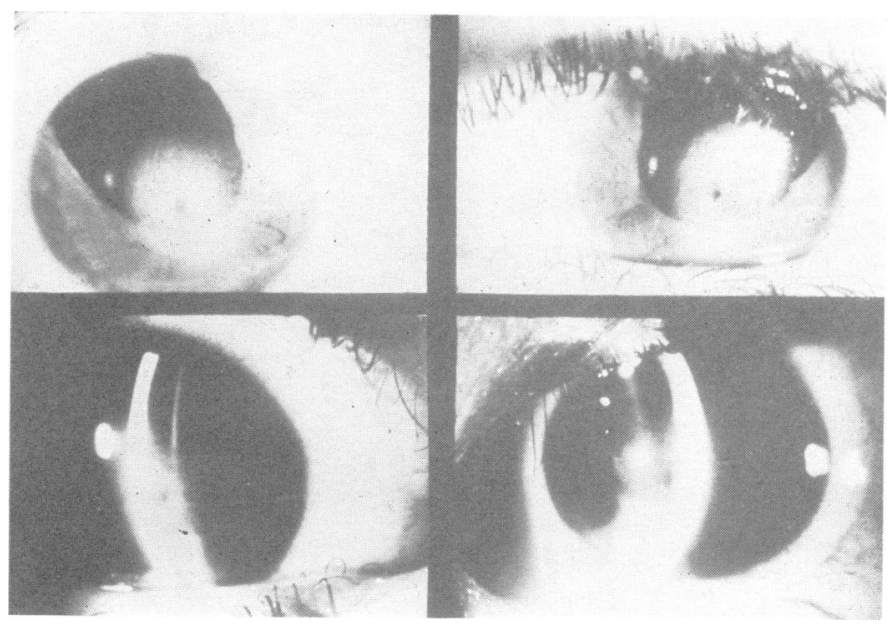

Fig 5 Naked eye and slit lamp views of the eyes of case 2 at $11 \frac{1}{2}$ years. The central corneal opacities are clearly visible. The child had undergone bilateral optical iridectomies when these pictures were taken.

Developmentally she first walked at 3 years and said meaningful words at $4 \frac{1}{2}$ years. Formal intellectual assessment at 5 years 9 months using the Stanford-Binet intelligence scale yielded a mental age of 3 to $3 \frac{1}{2}$ years (IQ 47-56). There has been no suggestion of regression and she has a very pleasant personality.

At recent examination growth parameters were: height $124 \mathrm{~cm}(24 \mathrm{~cm}$ below the 3rd centile), span $110 \mathrm{~cm}$, upper to lower segment ratio $1 \cdot 12$, weight $39 \mathrm{~kg}$, and head circumference $52.5 \mathrm{~cm}$. She was noted to have a prominent nose, a short webbed neck with low posterior hair line, a small left sided preauricular pit with hypoplastic lobules, brachydactyly with fifth finger clinodactyly, limitation of extension and supination at both elbows, bilateral trigger thumbs, and bilateral pes cavus. General examination was otherwise normal.

Visual examination revealed residual left sided ptosis, bilateral central corneal opacities (fig 5), and a large coloboma of the right disc. Best corrected vision was $20 / 400$ in the right eye and 20/200 in the left eye, with +6 dioptre hyperopia in each eye.

\section{INVESTIGATIONS}

Routine blood studies in these children have yielded normal results. These include full blood count, urea and electrolytes, liver function tests, calcium and phosphate, thyroid function tests, and amino-acid screen. Both children have normal chromosomes based on banded analysis of cultured lymphocytes. Chromosomal studies on lymphocytes from their mother have revealed the presence of an extra $X$ chromosome in all cells analysed. Electrocardiography in both children is normal. No excess mucopolysacchariduria has been noted. Dermatoglyphic analysis in both cases has shown distally placed axial triradii with normal total ridge counts.

Radiographic studies in case 1 at the age of 15 years showed multiple errors of segmentation and fusion in upper and lower thoracic vertebrae with a scoliosis convex to the right (fig 6). Bone age was delayed by approximately 4 years. Similar changes were noted in his sister, again involving upper and lower thoracic vertebrae. She also showed a delay in bone age. In addition, cone shaped epiphyses were noted at the middle phalanges of her index fingers with pseudoepiphyses at the base of the second metacarpals (fig 7). Intravenous pyelography revealed bilateral splitting of the renal pelvis with double ureters (fig 8).

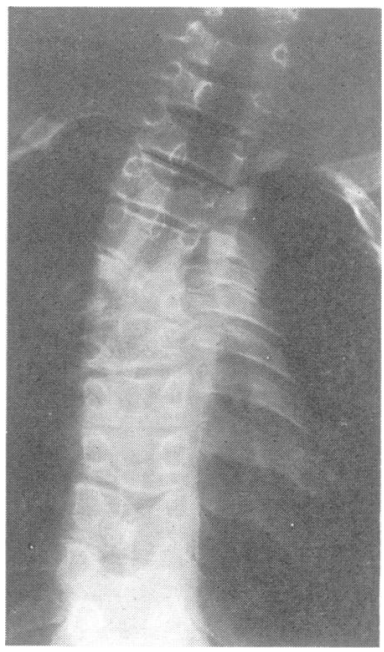

FIG 6 The thoracic spine of case 1. Note the multiple errors of segmentation and fusion. 


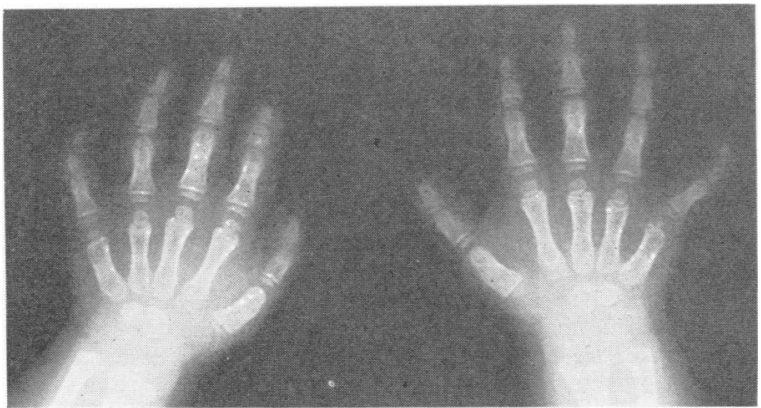

Fig 7 Hand $x$-rays of case 2 at 63 years of age. Note the delayed bone age, bilateral brachymesophalangia of the fifth fingers, and the pseudoepiphyses at the base of the second metacarpals. Note also the cone shaped epiphyses at the middle phalanges of the index fingers.

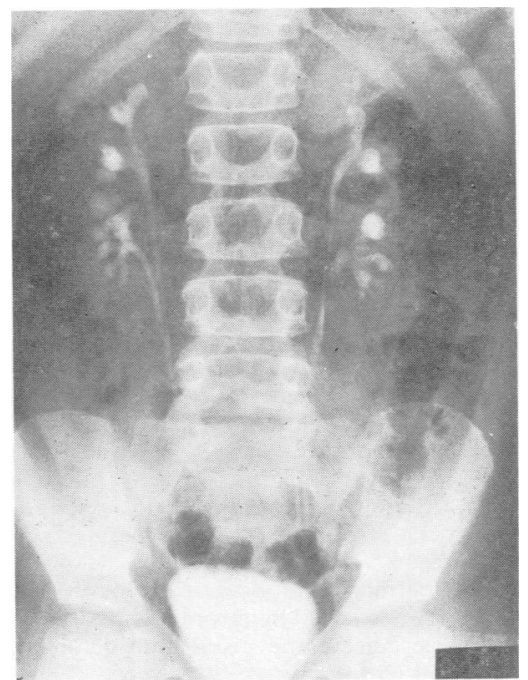

FIG 8 Intravenous pyelogram of case 2 aged 9 years. There is bilateral blunting of the calyces with duplication of the ureters. Micturating cystourethrogram showed bilateral reflux.

\section{Discussion}

The major clinical findings in these sibs are summarised in the table, perusal of which leaves little doubt that they are affected by the same disorder. Investigations have failed to reveal any chromosomal or metabolic abnormality. It is difficult to see how the trisomy $\mathrm{X}$ karyotype in their mother could be aetiologically relevant and it therefore seems most likely that this is coincidental.

The most striking feature in this unusual constellation of multiple malformations is the KPC. Several authors have suggested that this rare abnormality may be the sequel of an anterior chamber cleavage defect with failure of normal separation of the lens and iris from the cornea. ${ }^{1-3}$ The initial observations in the subjects of this report are consistent with this explanation, in that in
TABLE Summary of clinical and radiographical findings in cases 1 and 2

\begin{tabular}{lll}
\hline & Case 1 & Case 2 \\
\hline Corneal opacities & + & + \\
Retinal coloboma & + & + \\
Ptosis & - & + \\
Cleft lip and palate & + & + \\
Neck webbing & + & + \\
Short stature & + & + \\
Mental retardation & + & + \\
Inguinal herniae & + & - \\
Undescended testes & + & + \\
Tight heel cords & + & + \\
Vertebral anomalies & + & + \\
Delayed bone age & + & + \\
Double ureters & $?$ & + \\
Cone shaped epiphyses & - & + \\
\hline
\end{tabular}

case 1 the lenses were noted to be adjacent to the posterior surfaces of the corneae at the age of 3 days, and in case 2 adhesions extending from the irides to the corneae were noted at the age of 2 weeks.

Only rarely has KPC been described in more than one member of a family. In two reports both parent and child were affected. ${ }^{45}$ These patients were otherwise healthy. Haney and Falls ${ }^{6}$ described a brother and sister in each of whom KPC was associated with short stature, brachydactyly, and short stubby arms; in addition the sister showed neck webbing and was mentally retarded. We have recently learned of a 16-year-old girl with bilateral posterior keratoconus in addition to short stature, neck webbing, and cleft lip and palate. ${ }^{7}$ This patient has normal intelligence.

In Peters' anomaly there is a congenital corneal opacity with disruption of the deepest stromal layers and local absence of Descemet's membrane, possibly as a result of defective separation of the lens from the surface ectoderm. ${ }^{8}$ It has been suggested that KPC may constitute the mildest form of Peters' anomaly, ${ }^{9}$ which in isolation may show autosomal recessive inheritance. ${ }^{10}$ Although Peters' anomaly has been reported in association with other abnormalities, ${ }^{11-13}$ we have been unable to trace any 
report of its presence in a pattern of malformations similar to that described here. Similarly, corneal clouding may be a feature of several malformation syndromes, ${ }^{14-20}$ but in none of these do the findings correspond closely with those in the subjects of this report.

Thus, although the findings in our patients do bear some resemblance to those previously described, particularly the cases of Haney and Falls 6 and Streeten et al, ${ }^{7}$ in none of these cases do the clinical features overlap sufficiently to suggest an identical disorder. In conclusion, therefore, it is proposed that the multiple abnormalities in these sibs constitute a previously undescribed pleiotropic single gene disorder. Clearly the family history is most consistent with autosomal recessive inheritance.

We are most grateful to Professor B W Streeten and her colleagues for providing us with clinical details of their patient, and to Miss Allison Chiu for her invaluable secretarial assistance.

This paper was presented at the Clinical Genetics Society meeting in November 1981.

\section{References}

1 Krachmer JH. Posterior keratoconus. Arch Ophthalmol 1978;96:1867-73.

2 Hagedoorn A, Velzeboer CMJ. Postnatal partial spontaneous correction of a severe congenital anomaly of the anterior segment of an eye. Arch Opthalmol 1959;62: 685-93.

3 Charan H. Keratoconus posticus circumscriptus with indentation of the lens. $\mathrm{Br} J$ Ophthalmol 1967;51:486-8.

4 Jacobs HB. Posterior conical cornea. Br J Ophthalmol 1957;41:31-9.

5 Collier M. Le kératocône postérieur. Arch Ophthalmol (Paris) 1962;22:376-91

- Haney WP, Falls HF. The occurrence of congenital keratoconus posticus circumscriptus in two siblings presenting a previously unrecognised syndrome. Am J Ophthalmol 1961;52:53-7.

7 Streeten BW, Karpik AG, Spitzer KH. Posterior keratoconus associated with systemic abnormalities. Arch Ophthalmol (in press).

8 Townsend WM. Congenital corneal leukomas. 1. Central defect in Descemet's membrane. Am J Ophthalmol 1974; 77:80-6.

9 Alkemade PPH. Dysgenesis mesodermalis of the iris and the cornea. Assen: Van Gorcum, 1969.

10 Cross HE. Penetrance and variability in anterior chamber malformations. Birth Defects 1979;XV,No 5B:131-44.

11 Pagon RA, Chandler JW, Collie WR, et al. Hydrocephalus, agyria, retinal dysplasia, encephalocele (HARD \pm E) syndrome: an autosomal recessive condition. Birth Defects 1978 ;XIV,No 6B:233-41.

12 Ide $\mathrm{CH}$, Matta C, Holt JE, Felker GV. Dysgenesis mesodermalis of the cornea (Peters' anomaly) associated with cleft lip and palate. Ann Ophthalmol 1975;7:841-2.

13 Ruprecht KW, Majewski F. Familiäre arhinie mit Petersscher anomalie und kiefermissbildungen, ein neuts fehlbildungssyndrom? Klin Monatsbl Augenheilkd 1978; 172:708-15.

14 Pinsky, L, DiGeorge AM, Harley D, Baird HW. Microophthalmos, corneal opacity, mental retardation, and spastic cerebral palsy. An oculocerebral syndrome. J Pediatr 1965;67:387-98.

15 Mietens C, Weber H. A syndrome characterized by corneal opacity, nystagmus, flexion contracture of the elbows, growth failure, and mental retardation. $J$ Pediatr $1966 ; 69 ; 624-9$.

16 Cross HE, McKusick VA, Breen W. A new oculocerebral syndrome with hypopigmentation. J Pediatr 1967;70: 398-406.

17 Herrmann J, Feingold M, Tuffli GA, Opitz JM. A familial dysmorphogenetic syndrome of limb deformities, characteristic facial appearance and associated anomalies: the "pseudothalidomide" or "SC-syndrome". Birth Defects 1969;V, No 3:81-9.

18 Balci S, Say B, Firat T. Corneal opacity, microphthalmia, mental retardation, microcephaly and generalised muscular spasticity associated with hyperglycinemia. Clin Genet 1974;5:36-9.

19 Fryns JP, Moerman F, Goddeeris P, Bossuyt C, Van den Berghe H. A new lethal syndrome with cloudy corneae, diaphragmatic defects and distal limb deformities. Hum Genet 1979;50:65-70.

${ }^{20}$ Fryns JP, Van den Berghe $H$. Corneal clouding, subvalvular aortic stenosis, and midfacial hypoplasia associated with mental deficiency and growth retardation -a new syndrome? Eur J Pediatr 1979;131:179-83.

Requests for reprints to $\mathrm{Dr}$ W G Macrae, Department of Ophthalmology, The Hospital for Sick Children, 555 University Avenue, Toronto, Ontario, Canada M5G 1X8. 